\title{
Is Low Serum Vitamin D Associated with Early Dental Implant Failure? A Retrospective Evaluation on 1625 Implants Placed in 822 Patients
}

\author{
Francesco Mangano, ${ }^{1}$ Carmen Mortellaro, ${ }^{2}$ Natale Mangano, ${ }^{3}$ and Carlo Mangano ${ }^{4}$ \\ ${ }^{1}$ Department of Surgical and Morphological Science, Dental School, University of Insubria, 21100 Varese, Italy \\ ${ }^{2}$ Department of Health Sciences, University of Eastern Piedmont, 28100 Novara, Italy \\ ${ }^{3}$ Division of Endocrinology and Metabolism, Moriggia Pelascini Hospital, 22015 Gravedona ed Uniti, Italy \\ ${ }^{4}$ Department of Dental Sciences, University Vita Salute San Raffaele, 20132 Milan, Italy
}

Correspondence should be addressed to Francesco Mangano; francescomangano1@mclink.net

Received 1 June 2016; Revised 22 July 2016; Accepted 30 August 2016

Academic Editor: Marcos Minicucci

Copyright ( 2016 Francesco Mangano et al. This is an open access article distributed under the Creative Commons Attribution License, which permits unrestricted use, distribution, and reproduction in any medium, provided the original work is properly cited.

\begin{abstract}
Aim. To investigate whether there is a correlation between early dental implant failure and low serum levels of vitamin D. Methods. All patients treated with dental implants in a single centre, in the period 2003-2015, were considered for enrollment in this study. The main outcome was early implant failure. The influence of patient-related variables on implant survival was calculated using the Chi-square test. Results. 822 patients treated with 1625 implants were selected for this study; 27 early failures (3.2\%) were recorded. There was no link between gender, age, smoking, history of periodontitis, and an increased incidence of early failures. Statistical analysis reported 9 early failures (2.2\%) in patients with serum levels of vitamin D > $30 \mathrm{ng} / \mathrm{mL}$, 16 early failures (3.9\%) in patients with levels between 10 and $30 \mathrm{ng} / \mathrm{mL}$, and 2 early failures (9.0\%) in patients with levels $<10 \mathrm{ng} / \mathrm{mL}$. Although there was an increasing trend in the incidence of early implant failures with the worsening of vitamin D deficiency, the difference between these 3 groups was not statistically significant $(P=0.15)$. Conclusions. This study failed in proving an effective link between low serum levels of vitamin $\mathrm{D}$ and an increased risk of early implant failure. Further studies are needed to investigate this topic.
\end{abstract}

\section{Introduction}

Dental implants are now a reliable solution for the functional and esthetic rehabilitation of partially and completely edentulous patients; this has been demonstrated by long-term clinical trials, with survival rates of greater than 95\% [1-3].

In order to achieve long-term survival, osseointegration of the dental implant needs to occur; that is, a direct connection must be established between the bone and the implant surface, without the interposition of fibrous tissue [4]; once established, this close bond must be maintained over time, resulting in a clinically asymptomatic fixation of the implant under functional load [5]. Osseointegration is a complex phenomenon and depends on many factors; some are related to the implant (material, macroscopic design, and implant surface), others to the surgical-prosthetic protocol (surgical technique, loading conditions, and time), and others to the patient (quantity/quality of bone at the receiving site and the host response) $[4,5]$.

Although survival rates of dental implants are now high, there still remains a seemingly unavoidable number of failures: either cases in which correctly placed implants do not integrate with the bone or cases of peri-implant tissue infection $[6,7]$. To be specific, failure to osseointegrate and peri-implantitis are the most frequent causes of early implant failure $[3,6,7]$. Such events occur during the early stages of healing (within 2-3 months of implantation) and therefore before the implant is functionally loaded with the prosthetic restoration; these failures are unevenly distributed within the general population and tend to occur in some subjects in particular. In these individuals multiple or repeated failures over time are possible $[6,7]$. Early failures occur even when 
optimal materials are used, surgical protocols are strictly followed, and the quantity/quality of bone at the recipient site is sufficient [6-8]. All these observations would suggest the existence of specific patient-related risk factors; this prompts an investigation into the regulatory mechanisms controlling bone metabolism, bone remodelling, and bone turnover [ 9 , 10].

Vitamin D plays a fundamental role in bone metabolism [11-13]. It is a fat-soluble vitamin which promotes the absorption of calcium in the intestine and regulates calcium and phosphate homoeostasis in the tissues and it is a fundamental element in the mineralization of bones and teeth [11-13]. It also acts as a hormone and is vital for the health of the blood vessels and the brain $[14,15]$. It has been demonstrated that vitamin $\mathrm{D}$ plays a crucial role in the health of the cardiovascular tract [16], the immune system [17], and the respiratory tract $[18,19]$.

Vitamin D in an inactive form (cholecalciferol or vitamin D3) is ingested or produced in the skin on exposure to sunlight $[11,12]$. This inactive form undergoes double hydroxylation in the liver and the kidneys and is thereby transformed into its active form, known as either calcitriol or 1,25-dihydroxyvitamin D3 [11, 12]. This active form exerts its action on various tissues by binding to the vitamin $\mathrm{D}$ receptors and regulating the transcription of specific target genes [12-23].

Serum levels of vitamin D in the $25(\mathrm{OH}) \mathrm{D}$ form are the most accurate way of determining vitamin $\mathrm{D}$ status: a subject with $<10 \mathrm{ng} / \mathrm{mL}$ is considered to be vitamin $\mathrm{D}$ deficient; one with $10-30 \mathrm{ng} / \mathrm{mL}$ is considered to have low levels of vitamin $\mathrm{D}$. The optimal blood level of vitamin $\mathrm{D}$ is a value $>30 \mathrm{ng} / \mathrm{mL}[12,13]$. Vitamin D deficiency is high in the general population [12]: in Italy, for example, it is estimated that about $80 \%$ of people can be deficient, particularly in the northern regions where exposure to the sun is lower [20]. This deficiency increases with age and encompasses the majority of the elderly population of Italy who are not taking vitamin D supplements [20]. Until a few years ago, the guidelines estimated that the daily intake of vitamin $\mathrm{D}$ required to maintain adequate blood levels was $200 \mathrm{IU}$ ( $5 \mathrm{mcg}$ ) in adults aged between 19 and 50, $400 \mathrm{IU}(10 \mathrm{mcg})$ in adults aged between 51 and 69, and at least $600 \mathrm{IU}(15 \mathrm{mcg})$ in those over $70[12,13]$. These guidelines have now been revised upwards and it is currently believed that the amount of vitamin D which should be taken daily is $2000 \mathrm{IU}$ (50 mcg) and up to 4000 (100 mcg) in the case of, for example, pregnant women $[12,13]$.

There is now substantial literature on the negative effects of low levels of vitamin D, especially in severely compromised patients: vitamin D deficiency seems to be associated with increased mortality, cardiovascular events, and reduced functioning of the immune and musculoskeletal systems [1519, 21-23]. On the other hand, normalizing levels of vitamin D can lead to substantial benefits for critically ill patients, with effects on the muscles, the respiratory system, the heart, and the immune system $[18,21,23]$.

Despite the importance of vitamin $\mathrm{D}$ and its effects on bone metabolism [11, 12] few studies have, to date, investigated the effects of its depletion on the osseointegration of dental implants [9, 24-35]: almost all these studies have been done on animal models [24-32] and very few on humans [3335]. The purpose of this retrospective study was therefore to investigate any possible correlation between low blood levels of vitamin $\mathrm{D}$ and early implant failure (failure occurring in the four months prior to the full restoration of the implant, because of a lack of osseointegration or because of infection).

\section{Materials and Methods}

2.1. Data Collection. All patients who had been treated with Morse-taper connection dental implants (Leone ${ }^{\circledR}$ Implant System, Florence, Italy) [3, 8] inserted to support fixed prosthetic restorations in one single dental centre (Gravedona, Como, Italy), in the period between January 2003 and December 2015, were evaluated for possible enrollment into this retrospective study. Patients were enrolled into the study if they were over 18 years of age, had good oral and general health, and had not undergone bone regenerative therapy prior to implant placement. The exclusion criteria were incomplete medical records, the presence of specific systemic diseases (uncontrolled diabetes mellitus, immunodeficient states, and bleeding disorders), and the abuse of alcohol and drugs; patients undergoing radiotherapy and chemotherapy and those who were pregnant were also excluded. All the data used for the study were obtained from the medical records of the patients enrolled. The patient data was evaluated; this included gender (male or female), age at time of surgery, history of chronic periodontal disease, smoking habits, and serum vitamin D levels. Vitamin D levels were taken from blood tests, which had been requested two weeks prior to surgery. The medical records also contained a range of information as regards the implant or implants, that is, their site (maxilla or mandible), location (incisor, canine, premolar, and molar), the length and diameter of the implant, the type of prosthetic restoration, and the loading conditions. Lastly, the medical records contained all the information on any implant failure. These included their cause (lack of osseointegration in the absence of infection, infection of the periimplant tissues or peri-implantitis, or implant failure due to progressive bone loss caused by to prosthetic overload). It also included their classification: early failure, occurring in the early healing period, that is, the four months after implant placement, prior to the placement of restoration and loading, or late failure, occurring after loading. There were also details of any possible biological complications (periimplant mucositis and peri-implantitis) and/or prosthetic complications (mechanical and/or technical).

2.2. Insertion Protocol for the Implants. All implants were inserted under the same strict protocol by the same specialist (C. M.) who had 25 years' experience in implant dentistry, in the period between January 2003 and December 2015. The implants were inserted after raising a full thickness mucoperiosteal flap; the implant site preparation and implant placement were performed in compliance with modern surgical protocols and in accordance with the manufacturer's instructions. After placement, cover screw was positioned 
and the implants were submerged. Immediately after positioning, patients were prescribed antibiotic coverage with $2 \mathrm{~g}$ of amoxicillin (or $600 \mathrm{mg}$ of clindamycin in patients allergic to penicillins) for 6 days. Postoperative pain was controlled with nimesulide $100 \mathrm{mg}$ daily for 2 days. Patients were given detailed instructions on oral hygiene and were prescribed chlorhexidine $0.12 \%$ mouth rinse twice a day for 6 days. The patients were recalled for suture removal after 10 days. The implants were left to heal submerged for a total period of 4 months, to allow undisturbed healing and achieve osseointegration. After 4 months of undisturbed healing, the patient was recalled for the implant to be uncovered. The cover screw was replaced with the healing abutment, and sutures were positioned. Two weeks later, the sutures were removed and an impression was taken for the manufacture of the temporary restoration. The temporary restoration was maintained in situ for 3 months, in order to monitor the response of the implant, as well as the peri-implant tissues, to masticatory load; at the end of this period, the temporary restoration was replaced with the final restoration. The final restorations were metal porcelain, cemented with a zinc oxide-eugenol cement. A periapical radiograph was taken to check on the sealing of the restoration. All patients were included in a follow-up protocol with an annual check-up at one of the scheduled professional oral hygiene sessions.

2.3. Primary Outcome. Early implant failure, occurring within 4 months after implant placement and therefore prior to placement of the prosthetic restoration and the functional load of the implant, was the primary outcome studied. Early implant failures were divided into two different categories: (a) early failures due to lack of osseointegration and subsequent implant mobility, in the absence of clinical signs of infection; (b) early failures due to infection of the bone tissue around the implant, with inflammation (peri-implantitis) of periimplant tissues and the presence of fistula, pain, swelling, pus and/or exudate, pocket depth $>6 \mathrm{~mm}$ with bleeding, and marginal bone resorption $>2.5 \mathrm{~mm}$.

2.4. Statistical Analysis. All the data retrieved from the individual medical records were recorded on a generic

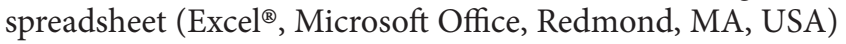
which was used for the descriptive, qualitative, and quantitative analyses. The mean, standard deviation, median, and confidence intervals were calculated for the quantitative variables (e.g., patients' age and vitamin D levels in serum). A patient-based technique was used to calculate implant survival. In this analysis, the "event" was implant failure: thus in patients receiving more than one implant, the occurrence of even a single implant failure led to the patient being classified as a "failure." The influence of different variables on implant survival was taken into consideration: gender (male or female), age at time of surgery (three age groups were examined: $<40,40-60$ years, and >60 years), smoking habits (regardless of the actual number of cigarettes smoked), a history of chronic periodontitis [36], and serum levels of vitamin $\mathrm{D}$. In the analysis of serum levels of vitamin $\mathrm{D}$, three classes of patients were considered: severely deficient patients (serum vitamin $\mathrm{D}<10 \mathrm{ng} / \mathrm{mL}$ ), patients with low levels (serum vitamin $\mathrm{D}$ between 10 and $30 \mathrm{ng} / \mathrm{mL}$ ), and patients with adequate levels (serum vitamin $\mathrm{D}>30 \mathrm{ng} / \mathrm{mL}$ ). The influence of each of these variables on implant survival was calculated using the Chi square test. The significance level was set at 0.05 . The overall implant survival, the survival within the different groups, and the analysis of the influence of the different variables on survival were all made using dedicated statistical analysis software (SPSS $17.0^{\circledR}$, SPSS Inc., Chicago, IL, USA).

\section{Results}

Of the 915 patients originally evaluated for enrollment in this study, 93 presented with conditions corresponding to the exclusion criteria and were therefore excluded from the assessment. By contrast, 822 patients (mean age $57.3 \pm 14.2$ years; median age 58; range 18-90; and 95\% CI, 56.3-58.2), receiving 1625 implants, did not have any of the conditions contained in the exclusion criteria and were therefore enrolled into this retrospective study. The distribution of patients by groups, with relative incidence of failures, was reported in Table 1. In total, 27 early failures were recorded (19 due to failure of osseointegration and 8 due to periimplant tissue infection), with an overall incidence of $3.2 \%$. No differences were observed in the incidence of early failures between males and females $(P=0.97)$ nor according to age at time of surgery $(P=0.98)$. Although the percentage of early failures in smokers was slightly higher than that detected in nonsmokers, there was no statistically significant difference $(P=0.56)$ between these two groups of patients. The same was true for patients with a history of periodontal disease; they displayed a slightly higher incidence of early failures than patients who had not been affected by periodontitis, but this difference was not significant $(P=0.73)$. The average serum level of vitamin $D$ in the general population was $29.9 \mathrm{ng} / \mathrm{mL}$ ( \pm 12.1 ; median 29 ; range $5-73$; and $95 \%$ CI, 29.1-30.7). In patients in whom early implant failure occurred, the average serum level of vitamin D was $25.5( \pm 13.2$; median 24 ; range 8-55; and 95\% CI, 20.6-30.4). Statistical analysis reported a rather low incidence of early failures $(2.2 \%)$ in patients with blood vitamin D levels $>30 \mathrm{ng} / \mathrm{mL}$. The incidence of early failure was almost double in patients with insufficient serum levels of vitamin $\mathrm{D}(10-30 \mathrm{ng} / \mathrm{mL})$ and became even higher $(9.0 \%)$ in patients with serious vitamin $\mathrm{D}$ deficiency. Although the statistical analysis revealed a trend toward an increased incidence of failure in patients with severe vitamin $\mathrm{D}$ deficiency, the analysis did not reveal a statistically significant difference $(P=0.15)$ in the incidence of early implant failure in these three groups of patients. Similar results $(P=0.14)$ were obtained comparing the incidence of failures in the group of severely deficient patients $(2 / 22$ : $9.0 \%)$ with the incidence of failures in all other patients (25/800: 3.1\%). Finally, the statistical analysis did not reveal a significant difference $(P=0.13)$ when comparing the incidence of failures in the group of patients with serum vitamin D levels $>30 \mathrm{ng} / \mathrm{mL}$ (9/394: 2.2\%) with the incidence of failures in all other patients (18/428: 4.2\%). The details of early failure were reported in Table 2. 
TABLE 1: Distribution of patients (by gender, age at surgery, smoking habit, history of periodontal disease, and vitamin D levels in serum), related failures, survival rate within groups, and differences between groups (Chi square test).

\begin{tabular}{|c|c|c|c|c|}
\hline & Number of patients & Early failures & Incidence of early failures & $P$ value* \\
\hline \multicolumn{5}{|l|}{ Gender } \\
\hline Males & 424 & 14 & $3.3 \%$ & \multirow{2}{*}{0.97} \\
\hline Females & 398 & 13 & $3.2 \%$ & \\
\hline \multicolumn{5}{|l|}{ Age at surgery } \\
\hline$<40$ years & 92 & 3 & $3.2 \%$ & \multirow{3}{*}{0.98} \\
\hline $40-60$ years & 380 & 12 & $3.1 \%$ & \\
\hline$>60$ years & 350 & 12 & $3.4 \%$ & \\
\hline \multicolumn{5}{|l|}{ Smoking habit } \\
\hline Yes & 261 & 10 & $3.8 \%$ & \multirow{2}{*}{0.56} \\
\hline No & 561 & 17 & $3.0 \%$ & \\
\hline \multicolumn{5}{|c|}{ History of periodontal disease } \\
\hline Yes & 279 & 10 & $3.5 \%$ & \multirow{2}{*}{0.73} \\
\hline No & 543 & 17 & $3.1 \%$ & \\
\hline \multicolumn{5}{|c|}{ Vitamin D level in serum } \\
\hline$<10 \mathrm{ng} / \mathrm{mL}$ & 22 & 2 & $9.0 \%$ & \multirow{3}{*}{0.15} \\
\hline $10-30 \mathrm{ng} / \mathrm{mL}$ & 406 & 16 & $3.9 \%$ & \\
\hline$>30 \mathrm{ng} / \mathrm{mL}$ & 394 & 9 & $2.2 \%$ & \\
\hline
\end{tabular}

Statistically significant difference $P<0.05$.

${ }^{*} P$ value $=$ Chi square test.

\section{Discussion}

A relatively small number of experimental studies has attempted to investigate the effects of vitamin $\mathrm{D}$ on the osseointegration of dental implants [24-32]. The majority of these studies would appear to indicate a positive effect of vitamin $\mathrm{D}$ on osseointegration, but it is not yet entirely clear whether supplementation would promote the healing of periimplant bone tissue clinically [24, 33-35].

A recent review of the literature on animal studies has shown that vitamin $\mathrm{D}$ supplementation can stimulate new bone formation and increase the contact between the bone and the surface of titanium implants [24]. Specifically, Kelly et al. demonstrated that vitamin D deficiency could significantly compromise the establishment of osseointegration of Ti6Al4V implants in rats [25]. Similar results were reported by Dvorak et al. [26]. In an experimental study on ovariectomized rats, the authors demonstrated that vitamin $\mathrm{D}$ deficiency could impair the formation of peri-implant bone; the normalization of blood levels via supplementation of vitamin D stimulated new bone formation [26]. Similar results were reported by Zhou et al., who found an increase in osseointegration in osteoporotic rats given vitamin $\mathrm{D}$ supplements [27], and $\mathrm{Wu}$ et al., who demonstrated an increase in the percentage of contact between bone and implant in diabetic rats given vitamin D supplements [28]. Finally, Liu et al. reported that the administration of vitamin $\mathrm{D}$ could increase the fixation of dental implants in mice suffering from chronic kidney disease [29].

A further possibility for study, in order to understand the effects of the administration of vitamin $\mathrm{D}$ on bone healing of the peri-implant tissues, is that of coating the implant surface with vitamin D [30-32]. Salomó-Coll et al. evaluated the effect of the topical application of vitamin D to the surface of implants inserted in postextraction sockets in dogs, with histological and histomorphometric analyses of tissues removed at 12 weeks [30]. Topical application of vitamin $\mathrm{D}$ increased the percentage of bone to implant contact of $10 \%$ [30]. Similarly promising results were reported by Cho et al. in a histological and histomorphometric study on rabbits, where the coating of anodized implant surfaces with a solution of poly(D,L-lactide-co-glycolide) PLGA and $1 \alpha, 25$-dihydroxyvitamin D3 $(1 \alpha, 25-(\mathrm{OH}) 2 \mathrm{D} 3)$ stimulated the apposition of new bone on fixtures [31]. Finally, in a further experimental work in rabbits, implants with a surface coated in 1,25-(OH)2D3 have shown an improved tendency to osseointegrate compared to noncoated implants; however, this difference was not statistically significant [32].

Unfortunately, very few clinical studies have so far investigated the effects of vitamin D deficiency on osseointegration and on bone regeneration in dentistry [33-35]. This is probably due to the fact that there are many factors which can determine the success or failure of dental implants; the attention of clinicians has been mostly focused on drawing up surgical and prosthetic protocols and identifying new materials and implant surfaces to improve osseointegration, rather than on the analysis of patient-related risk factors [6-9]. In a recent clinical work, Alvim-Pereira et al. found no relationship between polymorphism of the vitamin $\mathrm{D}$ receptor and implant failure [33]. In a randomized, controlled, double-blind study, Schulze-Späte et al. investigated the effects of supplementation with a combination of vitamin D3 (5000 IU) and calcium $(600 \mathrm{mg}$ ) on the formation of new bone following maxillary sinus lift [34]. Ten patients were assigned to the test group and given vitamin D and calcium; ten other patients were assigned to the control 
TABLE 2: Details of all early implant failures.

\begin{tabular}{|c|c|c|c|c|c|c|c|}
\hline Patient & Gender & Age at surgery & Smoking habit & $\begin{array}{c}\text { History of } \\
\text { periodontal } \\
\text { disease }\end{array}$ & $\begin{array}{l}\text { Vitamin D level } \\
\text { in serum }\end{array}$ & Type of failure & $\begin{array}{l}\text { Position of the } \\
\text { failed implant }\end{array}$ \\
\hline 1 & $\mathrm{M}$ & 66 & Yes & No & $20 \mathrm{ng} / \mathrm{mL}$ & FO & $\# 24$ \\
\hline 2 & $\mathrm{M}$ & 55 & No & No & $35 \mathrm{ng} / \mathrm{mL}$ & $\mathrm{FO}$ & $\# 25$ \\
\hline 3 & $\mathrm{~F}$ & 42 & No & No & $55 \mathrm{ng} / \mathrm{mL}$ & FO & $\# 14$ \\
\hline 4 & M & 38 & No & Yes & $48 \mathrm{ng} / \mathrm{mL}$ & $\mathrm{FO}$ & $\# 15$ \\
\hline 5 & $\mathrm{~F}$ & 57 & Yes & Yes & $45 \mathrm{ng} / \mathrm{mL}$ & PI & $\# 15$ \\
\hline 6 & $\mathrm{~F}$ & 76 & No & Yes & $24 \mathrm{ng} / \mathrm{mL}$ & FO & $\# 26$ \\
\hline 7 & M & 45 & Yes & No & $55 \mathrm{ng} / \mathrm{mL}$ & $\mathrm{FO}$ & $\# 17$ \\
\hline 8 & M & 56 & No & No & $10 \mathrm{ng} / \mathrm{mL}$ & PI & $\# 17$ \\
\hline 9 & $\mathrm{~F}$ & 58 & No & No & $8 \mathrm{ng} / \mathrm{mL}$ & $\mathrm{FO}$ & $\# 26$ \\
\hline 10 & M & 62 & Yes & Yes & $22 \mathrm{ng} / \mathrm{mL}$ & $\mathrm{FO}$ & $\# 25$ \\
\hline 11 & M & 45 & No & No & $12 \mathrm{ng} / \mathrm{mL}$ & FO & $\# 13$ \\
\hline 12 & M & 44 & No & No & $28 \mathrm{ng} / \mathrm{mL}$ & FO & $\# 21$ \\
\hline 13 & $\mathrm{~F}$ & 38 & No & No & $25 \mathrm{ng} / \mathrm{mL}$ & PI & $\# 16$ \\
\hline 14 & M & 69 & Yes & Yes & $24 \mathrm{ng} / \mathrm{mL}$ & PI & $\# 24$ \\
\hline 15 & $\mathrm{~F}$ & 74 & No & No & $25 \mathrm{ng} / \mathrm{mL}$ & $\mathrm{FO}$ & $\# 26$ \\
\hline 16 & M & 70 & Yes & No & $18 \mathrm{ng} / \mathrm{mL}$ & FO & $\# 27$ \\
\hline 17 & M & 69 & No & No & $33 \mathrm{ng} / \mathrm{mL}$ & FO & $\# 46$ \\
\hline 18 & $\mathrm{~F}$ & 58 & Yes & No & $32 \mathrm{ng} / \mathrm{mL}$ & FO & $\# 46$ \\
\hline 19 & $\mathrm{~F}$ & 46 & Yes & Yes & $12 \mathrm{ng} / \mathrm{mL}$ & PI & $\# 35$ \\
\hline 20 & M & 52 & No & Yes & $9 \mathrm{ng} / \mathrm{mL}$ & PI & $\# 33$ \\
\hline 21 & $\mathrm{~F}$ & 43 & No & Yes & $29 \mathrm{ng} / \mathrm{mL}$ & FO & $\# 46$ \\
\hline 22 & $\mathrm{~F}$ & 26 & No & No & $33 \mathrm{ng} / \mathrm{mL}$ & FO & \#37 \\
\hline 23 & $\mathrm{~F}$ & 68 & Yes & No & $12 \mathrm{ng} / \mathrm{mL}$ & PI & $\# 42$ \\
\hline 24 & M & 78 & Yes & No & $15 \mathrm{ng} / \mathrm{mL}$ & $\mathrm{FO}$ & $\# 35$ \\
\hline 25 & M & 65 & No & No & $22 \mathrm{ng} / \mathrm{mL}$ & $\mathrm{FO}$ & $\# 44$ \\
\hline 26 & $\mathrm{~F}$ & 66 & No & Yes & $20 \mathrm{ng} / \mathrm{mL}$ & FO & $\# 36$ \\
\hline 27 & $\mathrm{~F}$ & 70 & No & Yes & $18 \mathrm{ng} / \mathrm{mL}$ & PI & $\# 45$ \\
\hline
\end{tabular}

group and received only calcium [34]. Six to eight months after surgery for bone regeneration, bone samples were taken for histological analysis during implant placement [34]. Although supplementation with vitamin D3 would have increased the serum levels of vitamin D with potentially positive effects on bone remodelling at the cellular level, no statistically significant difference was demonstrated between the two groups at the histological level [34].

The results of our study would appear to suggest that a severe deficiency of vitamin $\mathrm{D}$ in the blood might be related to an increase in the incidence of early implant failure. In fact, the incidence of early implant failure was rather low (2.2\%) in patients with normalized levels of vitamin $\mathrm{D}$ in the blood $(>30 \mathrm{ng} / \mathrm{mL}$ ), rose to almost double (3.9\%) in patients with insufficient serum levels (10-30 ng/mL), and were rather high $(9.0 \%)$ in patients characterized by severe deficiency states. However, despite the tendency to an increased incidence of early failure in patients characterized by deficiency states, the differences between the three groups of patients were not statistically significant $(P=0.15)$.
Our study also confirms that the serum values of vitamin $\mathrm{D}$ in the local population are rather low: we found that the proportion of patients with insufficient levels was $49.4 \%$ and that the percentage with a severe deficiency was $2.7 \%$. The percentage of patients with adequate levels was $47.9 \%$. This is not surprising, as most of the patients treated came from northern Italy and southern Switzerland, regions where exposure to sunlight is somewhat reduced for long periods of the year. In the light of this, the administration of vitamin $\mathrm{D}$ in the weeks prior to placement of a dental implant could be useful, particularly in patients with severe deficiency states; in these patients, vitamin D supplementation should be maintained for the whole life, in order to guarantee a good remodelling of the bone around the implant.

This study has the distinction of being one of the first clinical studies carried out on a large number of patients to investigate the possibility of an association between low blood levels of vitamin $\mathrm{D}$ and the incidence of early failure in implantology. By restricting the analysis to early failures, occurring in the first period of healing and therefore prior 
to placement of the prosthetic restoration, we were able to focus our research and avoid a range of factors (linked to the restoration itself and the prosthetic load) which could have confused the issue in the study. It is, in fact, well known that implant survival and thus osseointegration depend on a large number of factors (related to the surgical and prosthetic protocol, the materials used, and lastly the patient) $[4,5]$ and it can be difficult to identify which of them might be determining the success or failure of the treatment [7]. In order to avoid this and to limit the confounding factors, the same materials were used for all the patients in this study (the same implant system for all the patients) $[1,3,8]$. In addition, the same surgical protocol was used, involving submerged healing in the absence of prosthetic loading [3]. Thus the only possible confounding factors were the different quantity and quality of bone at the implant receiving sites and the patients' responses: these are unavoidable factors. However, some of those categories of patients most at risk of implant failure (patients undergoing bone regeneration to create the conditions for the positioning of the implant fixtures or those with particular medical conditions which might increase the risk of treatment failure) were excluded in the present study.

This study has limits. It is a retrospective work, in which the number of patients having a severe deficiency of vitamin $\mathrm{D}$ in the blood was low (only 22); thus the presence of even just one less failure in this group would have led to quite different results. It is possible that some residual confounding may have biased the association between vitamin $\mathrm{D}$ and implant failures that we observed. For instance, this study did not investigate the influence of other patient-related factors (e.g., the bone quality) which can affect implant survival in the period immediately following implant placement. In addition, if subjects with low levels of vitamin $\mathrm{D}$ were also likely to receive more than 1 implant, their risk of being classified as "failures" may increase. However, no patient in this study experienced more than 1 failure, and the probability of implant failure was not higher $(1.5 \%$ versus $2.1 \%$ ) in presence of another implant. Therefore, randomized, controlled clinical trials are needed to confirm the presence of an association between low serum levels of vitamin D and an increase in the incidence of early failure in implantology. It would be appropriate to assess whether supplementation of vitamin $\mathrm{D}$ in the weeks before the operation could lead to a reduction in early failures, whether due to lack of osseointegration or implant infection. Further scientific studies with an appropriate design and a more rigorous statistical analysis will therefore be required in order to thoroughly investigate this issue.

\section{Conclusions}

Until now, very few studies, and those mainly on animal models, have involved assessing the influence of blood levels of vitamin D levels on the osseointegration of dental implants. Although most of these studies have shown that the administration of vitamin $\mathrm{D}$ can improve the healing of the peri-implant bone tissue, it is not yet clear whether vitamin D supplements can promote the osseointegration of dental implants. Our retrospective clinical study aimed to investigate if there is a link between low levels of vitamin D in the blood and an increased risk of early implant failures. Although the incidence of early implant failures was higher in patients with low serum levels of vitamin D, our study failed in proving an effective link between low levels of vitamin D in the blood and an increased risk of early implant failure. Further higher level studies (prospective controlled trials or, even better, randomized controlled clinical trials) with a more rigorous statistical analysis are therefore needed to investigate this issue. If an association between low serum levels of vitamin $\mathrm{D}$ and higher risk of early implant failure could be demonstrated, the clinician could give a set dose of vitamin $\mathrm{D}$ in the weeks before surgery, in order to normalize serum levels and obtain a positive effect on the healing process.

\section{Competing Interests}

The authors declare no conflict of interests for the present study.

\section{Acknowledgments}

The authors are grateful to Giovanni Veronesi, Ph.D., Department of Biostatistics, University of Varese, Italy, for help with writing this manuscript.

\section{References}

[1] C. Mangano, F. Iaculli, A. Piattelli, and F. Mangano, "Fixed restorations supported by Morse-taper connection implants: a retrospective clinical study with 10-20 years of follow-up," Clinical Oral Implants Research, vol. 26, no. 10, pp. 1229-1236, 2015.

[2] S. T. Becker, B. E. Beck-Broichsitter, C. M. Rossmann, E. Behrens, A. Jochens, and J. Wiltfang, "Long-term survival of straumann dental implants with tps surfaces: a retrospective study with a follow-up of 12 to 23 years," Clinical Implant Dentistry and Related Research, vol. 18, no. 3, pp. 480-488, 2016.

[3] F. Mangano, A. Macchi, A. Caprioglio, R. L. Sammons, A. Piattelli, and C. Mangano, "Survival and complication rates of fixed restorations supported by locking-taper implants: a prospective study with 1 to 10 years of follow-up," Journal of Prosthodontics, vol. 23, no. 6, pp. 434-444, 2014.

[4] R. Trindade, T. Albrektsson, and A. Wennerberg, "Current concepts for the biological basis of dental implants: foreign body equilibrium and osseointegration dynamics," Oral and Maxillofacial Surgery Clinics of North America, vol. 27, no. 2, pp. 175-183, 2015.

[5] A. Jemat, M. J. Ghazali, M. Razali, and Y. Otsuka, "Surface modifications and their effects on titanium dental implants," BioMed Research International, vol. 2015, Article ID 791725, 11 pages, 2015.

[6] B. R. Chrcanovic, J. Kisch, T. Albrektsson, and A. Wennerberg, "Factors influencing early dental implant failures," Journal of Dental Research, vol. 95, no. 9, pp. 995-1002, 2016.

[7] A. Monje, L. Aranda, K. T. Diaz et al., "Impact of maintenance therapy for the prevention of peri-implant diseases: a systematic review and meta-analysis," Journal of Dental Research, vol. 95, no. 4, pp. 372-379, 2016. 
[8] C. Mangano, F. Mangano, J. A. Shibli, M. Ricci, R. L. Sammons, and M. Figliuzzi, "Morse taper connection implants supporting 'planned' maxillary and mandibular bar-retained overdentures: a 5-year prospective multicenter study," Clinical Oral Implants Research, vol. 22, no. 10, pp. 1117-1124, 2011.

[9] J. Choukroun, G. Khoury, F. Khoury et al., "Two neglected biologic risk factors in bone grafting and implantology: high low-density lipoprotein cholesterol and low serum vitamin D," Journal of Oral Implantology, vol. 40, no. 1, pp. 110-114, 2014.

[10] L. F. Cooper, "Systemic effectors of alveolar bone mass and implications in dental therapy," Periodontology 2000, vol. 23, no. 1, pp. 103-109, 2000.

[11] J. A. MacLaughlin, R. R. Anderson, and M. F. Holick, "Spectral character of sunlight modulates photosynthesis of previtamin D3 and its photoisomers in human skin," Science, vol. 216, no. 4549, pp. 1001-1003, 1982.

[12] M. F. Holick, "High prevalence of vitamin D inadequacy and implications for health," Mayo Clinic Proceedings, vol. 81, no. 3, pp. 353-373, 2006.

[13] C. M. Weaver, C. M. Gordon, K. F. Janz et al., "The National Osteoporosis Foundation's position statement on peak bone mass development and lifestyle factors: a systematic review and implementation recommendations," Osteoporosis International, vol. 27, no. 4, pp. 1281-1386, 2016.

[14] P. P. D. Santos, B. P. M. Rafacho, A. D. F. Gonçalves et al., "Vitamin D induces increased systolic arterial pressure via vascular reactivity and mechanical properties," PLOS ONE, vol. 9, no. 6, Article ID e98895, 2014.

[15] J. T. Keeney and D. A. Butterfield, "Vitamin D deficiency and Alzheimer disease: common links," Neurobiology of Disease, vol. 84, pp. 84-98, 2015.

[16] D. Papandreou and Z.-T.-N. Hamid, "The role of vitamin D in diabetes and cardiovascular disease: an updated review of the literature," Disease Markers, vol. 2015, Article ID 580474, 15 pages, 2015.

[17] B. Prietl, G. Treiber, T. R. Pieber, and K. Amrein, "Vitamin D and immune function," Nutrients, vol. 5, no. 7, pp. 2502-2521, 2013.

[18] D. R. Thickett, T. Moromizato, A. A. Litonjua et al., "Association between prehospital vitamin D status and incident acute respiratory failure in critically ill patients: a retrospective cohort study," BMJ Open Respiratory Research, vol. 2, no. 1, Article ID e000074, 2015.

[19] C. Schnedl, H. Dobnig, S. A. Quraishi, J. D. McNally, and K. Amrein, "Native and active vitamin D in intensive care: who and how we treat is crucially important," American Journal of Respiratory and Critical Care Medicine, vol. 190, no. 10, pp. 11931194, 2014.

[20] G. Isaia, R. Giorgino, G. B. Rini, M. Bevilacqua, D. Maugeri, and S. Adami, "Prevalence of hypovitaminosis D in elderly women in Italy: clinical consequences and risk factors," Osteoporosis International, vol. 14, no. 7, pp. 577-582, 2003.

[21] K. Amrein, K. B. Christopher, and J. D. McNally, "Understanding vitamin D deficiency in intensive care patients," Intensive Care Medicine, vol. 41, no. 11, pp. 1961-1964, 2015.

[22] K. Amrein, C. Schnedl, A. Holl et al., "Effect of high-dose vitamin $\mathrm{D}_{3}$ on hospital length of stay in critically ill patients with vitamin D deficiency: the VITdAL-ICU randomized clinical trial," The Journal of the American Medical Association, vol. 312, no. 15, pp. 1520-1530, 2014.

[23] D. N. Gumieiro, B. P. Murino Rafacho, B. L. Buzati Pereira et al., "Vitamin D serum levels are associated with handgrip strength but not with muscle mass or length of hospital stay after hip fracture," Nutrition, vol. 31, no. 7-8, pp. 931-934, 2015.

[24] F. Javed, H. Malmstrom, S. V. Kellesarian, A. A. Al-Kheraif, F. Vohra, and G. E. Romanos, "Efficacy of vitamin D3 supplementation on osseointegration of implants," Implant Dentistry, vol. 25, no. 2, pp. 281-287, 2016.

[25] J. Kelly, A. Lin, C. J. Wang, S. Park, and I. Nishimura, "Vitamin D and bone physiology: demonstration of vitamin D deficiency in an implant osseointegration rat model," Journal of Prosthodontics, vol. 18, no. 6, pp. 473-478, 2009.

[26] G. Dvorak, A. Fügl, G. Watzek, S. Tangl, P. Pokorny, and R. Gruber, "Impact of dietary vitamin D on osseointegration in the ovariectomized rat," Clinical Oral Implants Research, vol. 23, no. 11, pp. 1308-1313, 2012.

[27] C. Zhou, Y. Li, X. Wang, X. Shui, and J. Hu, "1,25Dihydroxy vitamin $\mathrm{D}_{3}$ improves titanium implant osseointegration in osteoporotic rats," Oral Surgery, Oral Medicine, Oral Pathology and Oral Radiology, vol. 114, no. 5, pp. S174-S178, 2012.

[28] Y.-Y. Wu, T. Yu, X.-Y. Yang et al., "Vitamin D3 and insulin combined treatment promotes titanium implant osseointegration in diabetes mellitus rats," Bone, vol. 52, no. 1, pp. 1-8, 2013.

[29] W. Liu, S. Zhang, D. Zhao et al., "Vitamin D supplementation enhances the fixation of titanium implants in chronic kidney disease mice," PLoS ONE, vol. 9, no. 4, Article ID e95689, 2014.

[30] O. Salomó-Coll, J. E. Maté-Sánchez de Val, M. P. RamírezFernandez, F. Hernández-Alfaro, J. Gargallo-Albiol, and J. L. Calvo-Guirado, “Topical applications of vitamin D on implant surface for bone-to-implant contact enhance: a pilot study in dogs part II," Clinical Oral Implants Research, vol. 27, no. 7, pp. 896-903, 2016.

[31] Y. J. Cho, S. J. Heo, J. Y. Koak, S. K. Kim, S. J. Lee, and L. H. Lee, "Promotion of osseointegration of anodized titanium implants with a 1a,25-dihydroxyvitamin D3 submicron particle coating," The International Journal of Oral and Maxillofacial Implants, vol. 26, no. 6, pp. 1225-1232, 2011.

[32] Y. Naito, R. Jimbo, M. S. Bryington et al., “The influence of 1 $\alpha .25$-dihydroxyvitamin $\mathrm{D}_{3}$ coating on implant osseointegration in the rabbit tibia," Journal of Oral and Maxillofacial Research, vol. 5, no. 3, article e3, 2014.

[33] F. Alvim-Pereira, C. C. Montes, G. Thomé, M. Olandoski, and P. C. Trevilatto, "Analysis of association of clinical aspects and vitamin D receptor gene polymorphism with dental implant loss," Clinical Oral Implants Research, vol. 19, no. 8, pp. 786-795, 2008.

[34] U. Schulze-Späte, T. Dietrich, C. Wu, K. Wang, H. Hasturk, and S. Dibart, "Systemic vitamin D supplementation and local bone formation after maxillary sinus augmentation - a randomized, double-blind, placebo-controlled clinical investigation," Clinical Oral Implants Research, vol. 27, no. 6, pp. 701-706, 2016.

[35] G. Bryce and N. MacBeth, "Vitamin D deficiency as a suspected causative factor in the failure of an immediately placed dental implant: a case report," Journal of the Royal Naval Medical Service, vol. 100, no. 3, pp. 328-332, 2014.

[36] M. S. Zangrando, C. A. Damante, A. C. Sant'ana, M. L. R. De Rezende, S. L. Greghi, and L. Chambrone, "Long-term evaluation of periodontal parameters and implant outcomes in periodontally compromised patients: a systematic review," Journal of Periodontology, vol. 86, no. 2, pp. 201-221, 2015. 


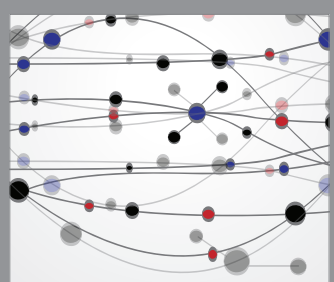

The Scientific World Journal
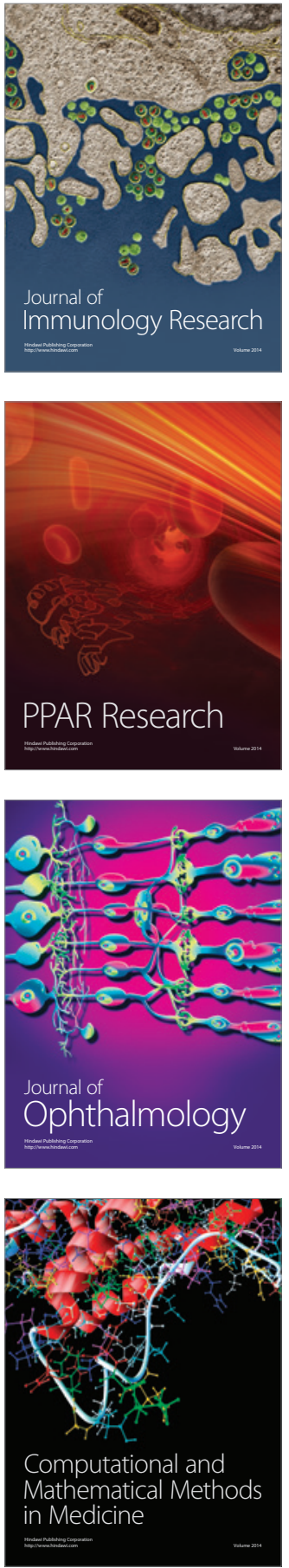

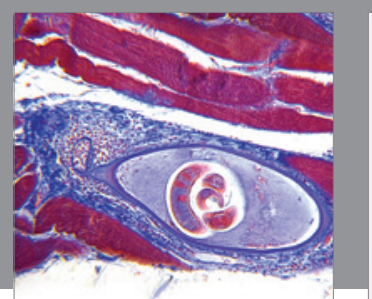

Gastroenterology Research and Practice

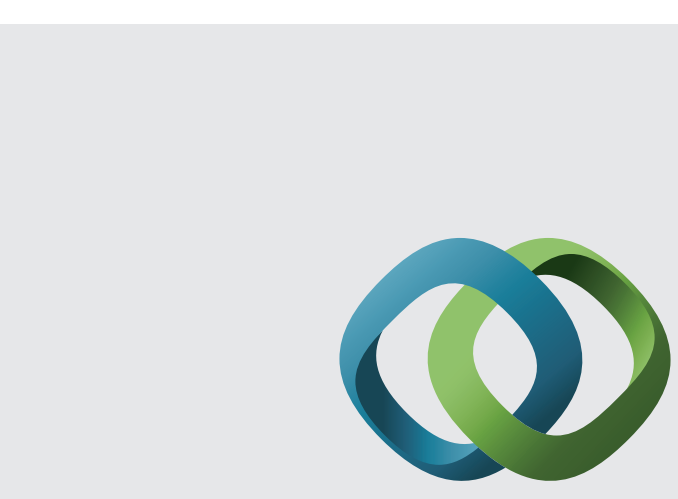

\section{Hindawi}

Submit your manuscripts at

http://www.hindawi.com
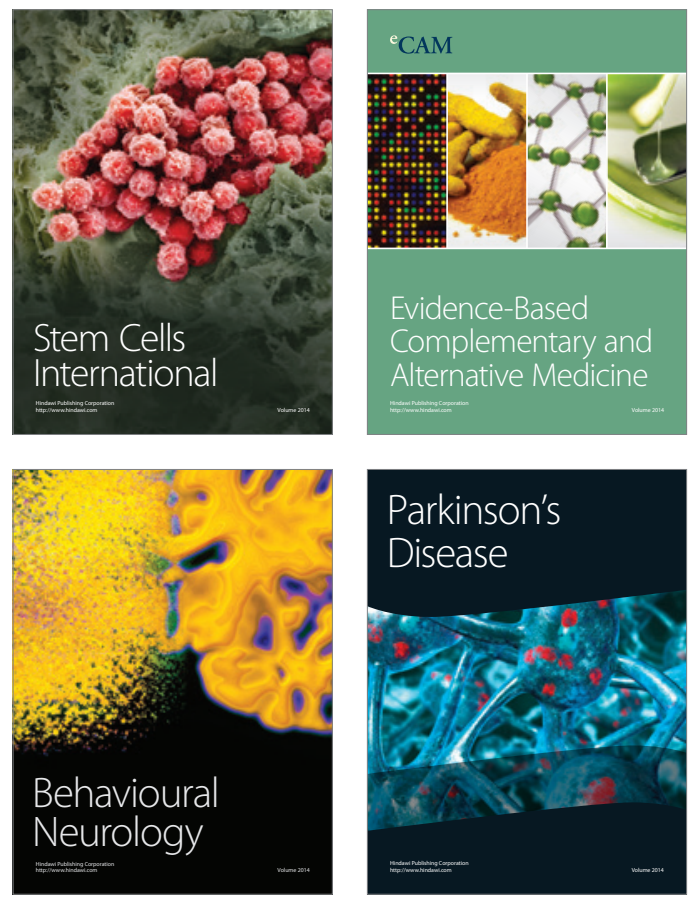
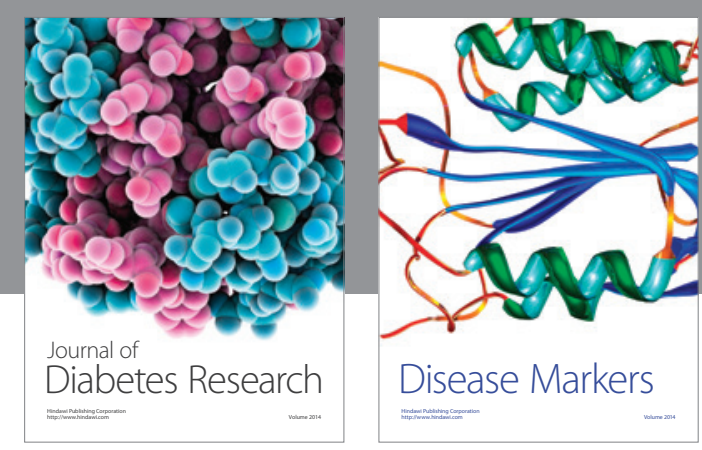

Disease Markers
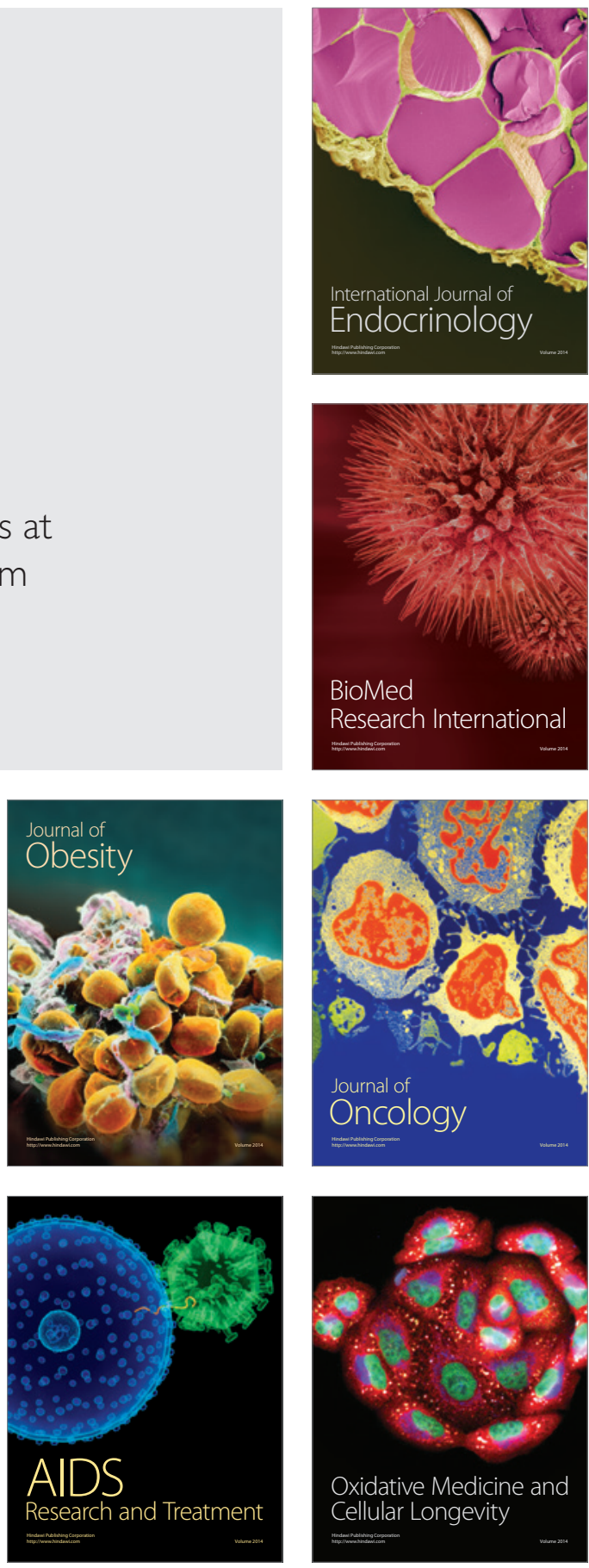